\title{
Factors Associated With Subjective Life Expectancy: Comparison With Actuarial Life Expectancy
}

\author{
Jaekyoung Bae', Yeon-Yong Kim², Jin-Seok Lee ${ }^{1,3}$ \\ ${ }^{1}$ Department of Health Management and Policy, Seoul National University College of Medicine, Seoul; ${ }^{2}$ Big Data Steering Department, National \\ Health Insurance Service, Wonju; ${ }^{3}$ Institute of Health Management and Policy, Seoul National University College of Medicine, Seoul, Korea
}

Objectives: Subjective life expectancy (SLE) has been found to show a significant association with mortality. In this study, we aimed to investigate the major factors affecting SLE. We also examined whether any differences existed between SLE and actuarial life expectancy (LE) in Korea.

Methods: A cross-sectional survey of 1000 individuals in Korea aged 20-59 was conducted. Participants were asked about SLE via a self-reported questionnaire. LE from the National Health Insurance database in Korea was used to evaluate differences between SLE and actuarial LE. Age-adjusted least-squares means, correlations, and regression analyses were used to test the relationship of SLE with four categories of predictors: demographic factors, socioeconomic factors, health behaviors, and psychosocial factors.

Results: Among the 1000 participants, women (mean SLE, 83.43 years; 95\% confidence interval, 82.41 to 84.46 years; $48 \%$ of the total sample) had an expected LE 1.59 years longer than that of men. The socioeconomic factors of household income and housing arrangements were related to SLE. Among the health behaviors, smoking status, alcohol status, and physical activity were associated with SLE. Among the psychosocial factors, stress, self-rated health, and social connectedness were related to SLE. SLE had a positive correlation with actuarial estimates $(r=0.61, p<0.001)$. Gender, household income, history of smoking, and distress were related to the presence of a gap between SLE and actuarial LE.

Conclusions: Demographic factors, socioeconomic factors, health behaviors, and psychosocial factors showed significant associations with SLE, in the expected directions. Further studies are needed to determine the reasons for these results.

Key words: Life expectancy, Socioeconomic factors, Health behavior, Republic of Korea

\section{INTRODUCTION}

Subjective (or self-estimated) life expectancy (SLE) is an individual's expectation regarding the perceived extent of his or

Received: March 3, 2017 Accepted: May 31, 2017

Corresponding author: Jin-Seok Lee, MD, PhD

103 Daehak-ro, Jongno-gu, Seoul 03080, Korea

Tel: +82-2-740-8362, Fax: +82-2-743-2009

E-mail: phealth@snu.ac.kr

This is an Open Access article distributed under the terms of the Creative Commons Attribution Non-Commercial License (http://creativecommons.org/licenses/by$\mathrm{nc} / 4.0 /$ ) which permits unrestricted non-commercial use, distribution, and reproduction in any medium, provided the original work is properly cited. her remaining years [1,2]. SLE is related to actual life expectancy (LE), mortality, and health status, but an individual's expectation of survival goes beyond health [3]. SLE is "a critical indicator of a highly complex attitude toward an emotionally charged topic in our society" [4], providing guidance for apportioning work, leisure, and finances within an adjusted timeframe [5].

An extensive literature has documented the ways in which SLE affects individuals' behavior. SLE has a strong effect on intended retirement age [6-8], even after controlling for demographic factors such as gender, age, income, education, health, marital status, and family longevity [9]. Increasing the length of life creates assurances about the future by reinforcing 
healthy habits [3]. Non-smokers and those who exercise regularly estimate their longevity to be longer [10], whereas people who drink heavily and those with poor nutritional habits expect shorter lives [3].

SLE has been used as a predictor of socioeconomic status and mortality. Individuals who expect to live longer lives achieve higher socioeconomic status, as assessed using educational goals, history of prolonged unemployment, current employment and occupational status, spouse's employment status, household income, and current or past economic hardship [11]. SLE has an independent effect on mortality [12], especially among older people [13].

A small number of prior studies found a positive correlation between SLE and actuarial LE because both depend considerably on current age $[10,14]$. However, differences between SLE and actuarial estimations are the focus of an ongoing debate. When SLE exceeds actuarial LE, it is due to participants' past increases in longevity [15], because people are extrapolating their past longevity when subjectively evaluating their future [16]. There are four hypotheses for these unresolved issues: (a) the age congruity hypothesis, (b) the cohort-improvement hypothesis, (c) the gender-anomaly hypothesis, and (d) the raceanomaly hypothesis; these hypotheses may explain differences according to age, gender, and race, respectively [17]. Two other main possible factors also discussed in the decision-theoretic literature are cognitive shortcomings and motivational reasons [18].

Because only a single study [19] has examined the relationships among SLE, socioeconomic status, and actuarial LE in Korea, it is important to analyze the effects of demographic, behavioral, and psychosocial factors on SLE, and to replicate such findings with nationally representative data across different age groups.

Based on the previously published literature, we hypothesize 1) that those with high SLE will exhibit several specific demographic, socioeconomic, health behavior-related, and psychological factors; and 2) that the difference between SLE and actuarial LE will be related to those factors.

\section{METHODS}

\section{Study Population and Data Collection}

A nationwide online panel survey of 1000 adults was conducted by the Research \& Research organization on behalf of the Ministry of Health and Welfare of Korea. Participants were recruited across Korea between August and September 2015, and all respondents gave consent for administering the survey via e-mail. Stratified sampling was used to select 1000 participants based on gender, age, and the postal area. In the sample allocation, proportional allocation was applied to correspond with the population and sample distribution ratios using stratification variables. All participants responded via e-mail to a survey questionnaire on a wide range of health and demographic indicators (response rate, 100\%). Altogether, the survey contained six sections of questions (general characteristics, health behavior, health service use, social environment, social medicine, patient choice of hospital), with a total of 24 items to be completed. Inclusion criteria were being between 19 years old and 59 years old, inclusive. The study protocol was approved by the institutional review board (IRB) at Seoul National University Hospital, Seoul, Korea (IRB no. 1508-064694).

\section{Measures}

\section{Subjective life expectancy}

In general, two common elicitation formats are distinguished. The first approach is a direct measurement of the point estimate of SLE, and the second approach is the percentage chance of living to a certain age [20]. While the direct method is simple and straightforward, the indirect assessment can capture uncertainty easily [21]. Based on the answer to the question, "to what age do you expect to live?", responses were given as age in years.

\section{Demographic variables}

Gender (1, men; 0, women), age, and health conditions were included in this category. Age was measured as a continuous variable in years, and identified by the unique registration number of each Korean resident. Health conditions referred to ever having received a diagnosis of any of the following 12 conditions: hypertension, hyperlipidemia, angina pectoris, osteoarthritis, lung tuberculosis, asthma, diabetes mellitus, thyroid disease, cancer, depression, liver cirrhosis, and renal failure. This information was elicited via an adaptation of the Korean Community Health Survey 2016 questionnaire [22].

\section{Socioeconomic variables}

Variables within this category of predictors included 1) residential area, 2) household income, 3) educational qualifications, 4) occupation, 5) the type of real estate contract through 
which the respondent obtained housing, and 6) the type of insurance. Residential areas were recoded as follows: 1, metropolitan area; 2, urban area; and 3, rural area [23]. Household income was defined as income per month in Korean won (KRW) after taxes, and was categorized on a scale ranging from $1(<2$ 000000 KRW per month) to 4 (>6000 000 KRW per month) [24]. The highest educational qualification (from 1 [high school diploma or lower] to 3 [graduate school degree or higher]) [25] and current occupation (1, manual; 2, non-manual; 3, others) were obtained. The type of real estate contract was coded as 1 (freely offered housing), 2 (monthly rent), 3 (lease), and 4 (ownership), and the type of insurance was coded as 1 (medical aid), 2 (community-based insurance), or 3 (work-based insurance).

\section{Health behavior variables}

The health behavior variables were: 1 ) history of smoking (1, current smoker; 2, ex-smoker; 3, never smoker); 2) alcohol consumption (1, 0 drinks per month; 2, 1-4 drinks per month; 3 , 2-3 drinks per week; 4, 4 or more drinks per week), using an adaptation of the National Health and Nutrition Examination Survey from the Korea Centers for Disease Control and Prevention; and 3) physical activity (1, 2 or fewer days with physical exercise per week; 2,3 or more days with physical exercise per week) [26-28].

\section{Psychosocial variables}

The following variables were assessed. Psychological distress was measured through a question asking "How often do you feel hopeless?" Subjects reported the frequency of each experience on a 4-point scale ranging from 'most of the time' to 'none of the time,' which is an adaptation of the Kessler Psychological Distress Scale [29]. Depression was assessed by determining whether participants had ever been diagnosed with depression. Social connectedness was measured by asking participants "Do you have the opportunity to spend time with family, friends, or any other social group?" Self-rated health reflects an individual's psychological state [30]. The question about perceived health asked "In general, how would you rate your health?" [31]. Responses were coded on a scale ranging from 1 (poor) to 5 (excellent) [32].

\section{Statistical Analysis}

Initially, we estimated the unadjusted mean age and 95\% confidence intervals ( $\mathrm{Cls}$ ) of the 4 proposed categories of SLE predictors to assess the correlations of individual variables with
SLE. We then estimated the age-adjusted least-squares means (LSMEANS) age of SLE using the genmod procedure and LSMEANS statement, as age was expected to change the relationship of socioeconomic status factors with SLE. The $t$-test and analysis of variance (ANOVA), according to both general and occupational characteristics, were performed. This analysis was conducted separately for men and women. The descriptive statistics of samples, mean SLE, age-adjusted LSMEANS $S L E$, and $t$-test and ANOVA analyses of each set of factors are provided in Tables 1 and 2.

Second, the correlation between SLE and actuarial LE was evaluated using the Pearson correlation coefficient. The Pearson correlation evaluates the linear relationship between two continuous variables. Actuarial LE was obtained from Statistics Korea [33]. We matched SLE and actuarial LE with participants' age and gender.

Finally, the characteristics of those who appeared to have underrated or overrated their LE were examined [1]. We recoded this difference variable to create three groups: (a) participants whose SLE was within 5-year of their actuarial estimate, (b) participants whose SLE was greater by 5 -year or more than their actuarial estimate (overestimated SLE), and (c) participants whose SLE was lower by 5 -year or more than the actuarial estimate (underestimated SLE). Multinomial logistic regression was used to identify factors that distinguished these groups in a separate analysis.

All analyses were performed using SAS version 9.4 (SAS Institute Inc., Cary, NC, USA). Statistical testing was conducted with a conventional 2-tailed alpha level of 0.05 .

\section{RESULTS}

\section{Tests of the four Sets of Variables}

Men comprised $52.0 \%$ of the sample. The average age of the participants was 42.03 years, and the average SLE was 82.70 years. When asked to estimate the LE of participants of their gender, women estimated their LE to be 83.43 years $(95 \% \mathrm{Cl}$, 82.41 to 84.46 years), while men estimated it to be 81.84 years ( $95 \% \mathrm{Cl}, 80.72$ to 82.96 years), yielding a difference of 1.59 years. Age showed a J-shaped relationship with SLE. People with a disease estimated a shorter LE, and $48.0 \%$ said they had an illness that would limit their LE.

Two variables, household income and the type of real estate contract, were significant socioeconomic factors. We found regions where income was not related to SLE in the expected di- 


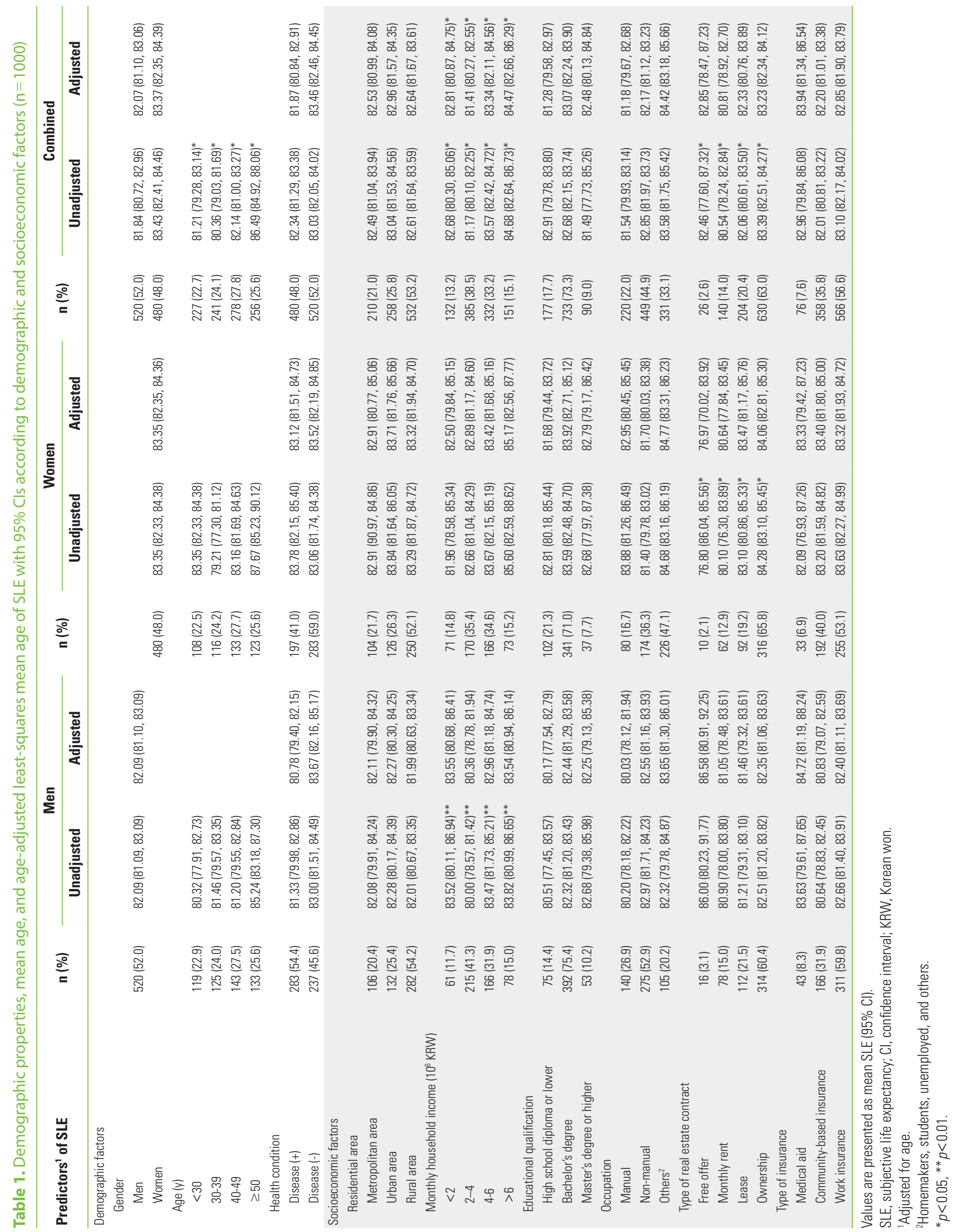




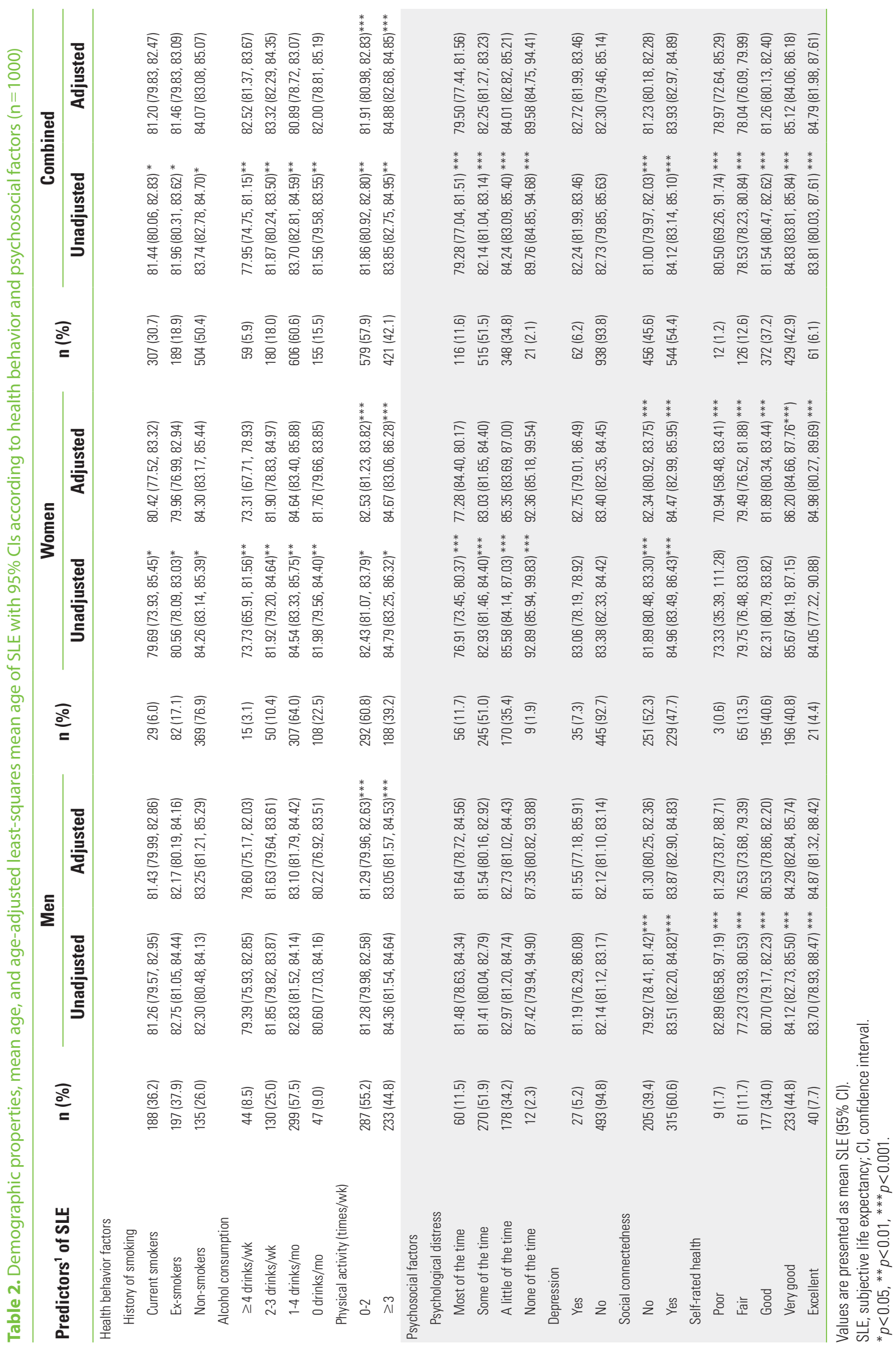


rection. In $86.8 \%$ of participants whose income was over 2 million KRW per month, a higher household income was associated with a higher expectation of life. Of these respondents, $82.3 \%$ had graduated from a university. In individuals overall, SLE was not significantly associated with educational qualifications, but we generally found that people with higher educational qualifications estimated their LE optimistically. The ageadjusted least-squares mean of educational qualifications showed a clearer gap than did the mean that was not age-adjusted. This occurred because, in Korea, older people are more likely to have less formal education than younger people. Occupation was not statistically significant. For men, $52.9 \%$ had a non-manual occupation, $26.9 \%$ engaged in manual labor, and only $20.2 \%$ were classified as 'other.' In contrast, almost half of the women were classified as 'other' because homemakers were included in this variable. The non-manual labor group expected their LE to be longer than did the manual labor group, and the 'others' group showed more optimistic expectations. The type of real estate contract was significantly related to SLE: 63.0\% owned their dwelling, and they had the most optimistic attitude about their LE. Of the respondents, $56.6 \%$ had workbased insurance, and $36.8 \%$ had community-based insurance. People covered by work-based insurance estimated a longer LE than people covered by community-based insurance.

All three variables in the health behavior category (history of smoking, alcohol consumption, and physical activity) showed significant relationships in the hypothesized direction. Current smokers, ex-smokers, and non-smokers comprised 36.2, 37.9, and $26.0 \%$ of the sample, respectively. Non-smokers were likely to estimate their LE to be higher than current smokers by 2.30 years.

The psychosocial factors of psychological distress, social connectedness, and self-rated health were significantly related to SLE in the expected direction. Participants who felt distressed most of the time estimated their $\mathrm{LE}$ as 79.28 years $(95 \% \mathrm{Cl}$, 77.04 to 81.51 years), while participants who felt distressed none of the time estimated theirs as 89.76 years $(95 \% \mathrm{Cl}, 84.85$ to 94.68 years), yielding a difference of 10.48 years. Depression was not a significant factor, while the $54.4 \%$ of participants who reported strong social connectedness had an SLE that was 3.12 years higher. For self-related health, responses of poor, fair, good, very good, and excellent were provided by 1.2, 12.6, 37.2, 42.9 , and $6.1 \%$ of the sample, respectively. People who answered 'fair' had the most pessimistic SLE estimates, and those who answered 'excellent' had the most optimistic estimations.
Table 3. Correlation between actuarial LE and SLE

\begin{tabular}{lccc}
\hline & \multicolumn{3}{c}{ Pearson correlation coefficient } \\
\cline { 2 - 4 } & Men & Women & Combined \\
\hline Actuarial life expectancy vs. SLE & $0.53^{* * *}$ & $0.49^{* *}$ & $0.61^{* * *}$ \\
\hline
\end{tabular}

$L E$, life expectancy; SLE, subjective life expectancy. ${ }^{* *} p<0.01,{ }^{* * *} p<0.0001$.

\section{Comparison Between Subjective Life Expectancy and Actuarial Life Expectancy}

As shown in Table 3, the Pearson correlation test showed a positive correlation between SLE and actuarial LE using the 2015 Korean life tables for men and women $(r=0.61, p<0.001)$.

Table 4 shows the demographic properties of the four factors associated with the presence of a gap between SLE and actuarial LE. Of the participants, $41.7 \%$ reported an SLE within 5 -year of their actuarial LE, $25.3 \%$ underestimated it by 5 -year or more, and $33.0 \%$ reported an SLE that was 5 or more years greater than their actuarial estimate.

Table 5 presents the multiple regression analyses of factors explaining the gap between SLE and actuarial estimates. We formed the reference group from participants with an SLE within 5-year of their actuarial LE. Having a disease and experiencing distress increased the odds of underestimating one's LE by 31.0 and $39.0 \%$, respectively. Being optimistic about one's health increased the odds of overestimating one's LE by $69.0 \%$. Other significant factors were gender, household income, history of smoking, depression, and social connectedness.

\section{DISCUSSION}

In this article, we studied the impact of demographic, socioeconomic, health behavior, and psychosocial factors on SLE in a cross-sectional study of 1000 people in Korea aged 19-59. The results support our hypothesis that demographic, socioeconomic, health behavior, and psychosocial factors would influence individuals' expectations of their remaining lifetime and the difference between SLE and actuarial estimates.

Demographic factors were related to SLE in ways consistent with prior research and actual LE. Women expected a higher LE than men did. However, compared to the 2015 Korean life tables, women reported an SLE that was 1.77 years lower than the actuarial estimate, while men had an SLE that was 2.84 years higher. These findings suggest that women tend to be more accepting of the reality of death than men [4]. Perhaps this is because men in Korea consider themselves to be more 
Table 4. Descriptive statistics for predictors of SLE, including demographic factors, health conditions, socioeconomic factors, and psychosocial factors, for the full sample and according to the gap between SLE and actuarial LE

\begin{tabular}{|c|c|c|c|}
\hline Predictors of SLE & SLE $\leq 5$ y of LE $(n=253)$ & SLE within 5 y of LE $(n=417)$ & SLE $\geq 5$ y of $L E(n=330)$ \\
\hline \multicolumn{4}{|l|}{ Demographic factors } \\
\hline \multicolumn{4}{|l|}{ Gender } \\
\hline Men & $147(58.1)$ & $201(48.2)$ & $172(52.1)$ \\
\hline \multicolumn{4}{|l|}{ Age (y) } \\
\hline$<30$ & $49(19.4)$ & $98(23.5)$ & $80(24.2)$ \\
\hline $30-39$ & $86(34.0)$ & $87(20.9)$ & $68(20.6)$ \\
\hline$\geq 50$ & $53(21.0)$ & $105(25.2)$ & $98(29.7)$ \\
\hline \multicolumn{4}{|l|}{ Health condition } \\
\hline Disease (+) & $141(55.7)$ & $194(46.5)$ & $145(43.9)$ \\
\hline Disease (-) & $112(44.3)$ & $223(53.5)$ & $185(56.1)$ \\
\hline \multicolumn{4}{|l|}{ Socioeconomic factors } \\
\hline \multicolumn{4}{|l|}{ Residential area } \\
\hline \multicolumn{4}{|c|}{ Monthly household income (10 $\left.10^{6} \mathrm{RW}\right)$} \\
\hline$<2$ & $36(14.2)$ & $47(11.3)$ & $49(14.9)$ \\
\hline $2-4$ & $116(45.9)$ & $163(39.1)$ & $106(32.1)$ \\
\hline $4-6$ & $68(26.9)$ & $153(36.7)$ & $111(33.6)$ \\
\hline$>6$ & $33(13.0)$ & $54(12.9)$ & $64(19.4)$ \\
\hline \multicolumn{4}{|l|}{ Educational qualification } \\
\hline High school diploma or lower & $57(22.5)$ & $63(15.1)$ & $57(17.3)$ \\
\hline Bachelor's degree & $174(68.8)$ & $320(76.7)$ & $239(72.4)$ \\
\hline Master's degree or higher & $22(8.7)$ & $34(8.2)$ & $34(10.3)$ \\
\hline \multicolumn{4}{|l|}{ Occupation } \\
\hline Manual & $62(24.5)$ & $95(22.8)$ & $63(19.1)$ \\
\hline Medical aid & $21(8.3)$ & $28(6.7)$ & $27(8.2)$ \\
\hline Community-based insurance & $130(51.4)$ & $246(59.0)$ & $190(57.6)$ \\
\hline Work-based insurance & $102(40.3)$ & $143(34.3)$ & $113(34.2)$ \\
\hline \multicolumn{4}{|l|}{ Health behavior factors } \\
\hline \multicolumn{4}{|l|}{ History of smoking } \\
\hline Current smokers & $180(54.5)$ & $220(52.8)$ & $104(41.1)$ \\
\hline Ex-smokers & $55(16.7)$ & $84(20.1)$ & $50(19.8)$ \\
\hline Non-smokers & $95(28.8)$ & $113(27.1)$ & $99(39.1)$ \\
\hline \multicolumn{4}{|l|}{ Alcohol consumption } \\
\hline$\geq 4$ drinks/wk & $23(9.1)$ & $20(4.8)$ & $16(4.9)$ \\
\hline 2-3 drinks/wk & $51(20.2)$ & $81(19.4)$ & $48(14.6)$ \\
\hline 1-4 drinks/mo & $135(53.4)$ & $252(60.4)$ & $219(66.4)$ \\
\hline 0 drinks/mo & $44(17.4)$ & $64(15.4)$ & $47(14.2)$ \\
\hline \multicolumn{4}{|l|}{ Physical activity (times/wk) } \\
\hline $0-2$ & $107(42.3)$ & $162(38.9)$ & $111(33.6)$ \\
\hline$\geq 3$ & $146(57.7)$ & $255(61.1)$ & $219(66.4)$ \\
\hline
\end{tabular}


Table 4. Continued from the previous page

\begin{tabular}{|c|c|c|c|}
\hline Predictors of SLE & SLE $\leq 5$ y of LE $(n=253)$ & SLE within 5 y of LE $(n=417)$ & SLE $\geq 5$ y of $L E(n=330)$ \\
\hline \multicolumn{4}{|l|}{ Psychosocial factors } \\
\hline \multicolumn{4}{|l|}{ Psychological distress } \\
\hline Most of the time & $48(19.0)$ & $38(9.1)$ & $30(9.1)$ \\
\hline Some of the time & $139(54.9)$ & $217(52.0)$ & $159(48.2)$ \\
\hline A little of the time & $64(25.3)$ & $157(37.7)$ & $127(38.5)$ \\
\hline None of the time & $2(0.8)$ & $5(1.2)$ & $14(4.2)$ \\
\hline \multicolumn{4}{|l|}{ Depression } \\
\hline No & $230(90.9)$ & $405(96.4)$ & $306(92.7)$ \\
\hline Yes & $23(9.1)$ & $15(3.6)$ & $24(7.3)$ \\
\hline \multicolumn{4}{|l|}{ Social connectedness } \\
\hline No & $130(51.4)$ & $201(48.2)$ & $125(37.9)$ \\
\hline Yes & $123(48.6)$ & $216(51.8)$ & $205(62.1)$ \\
\hline \multicolumn{4}{|l|}{ Self-rated health } \\
\hline Poor & $6(2.4)$ & $1(0.2)$ & $5(1.5)$ \\
\hline Fair & $63(24.9)$ & $39(9.4)$ & $24(7.3)$ \\
\hline Good & $102(40.3)$ & $179(42.9)$ & $91(27.6)$ \\
\hline Very good & $72(28.5)$ & $177(42.5)$ & $180(54.6)$ \\
\hline Excellent & $10(4.0)$ & $21(5.0)$ & $30(9.1)$ \\
\hline
\end{tabular}

Values are presented as number (\%).

SLE, subjective life expectancy; LE, life expectancy; KRW, Korean won.

Table 5. Multinomial logistic regression, using the group whose SLE was within 5 years of their actuarial estimate as the reference category

\begin{tabular}{|c|c|c|c|c|c|c|c|c|}
\hline & \multicolumn{4}{|c|}{ SLE $\leq 5$ y of LE } & \multicolumn{4}{|c|}{ SLE $\geq 5$ y of LE } \\
\hline & \multirow{2}{*}{$\boldsymbol{\beta}$} & \multirow{2}{*}{$\operatorname{Exp} \beta$} & \multicolumn{2}{|c|}{$95 \% \mathrm{CI}$} & \multirow{2}{*}{$\boldsymbol{\beta}$} & \multirow{2}{*}{$\operatorname{Exp} \beta$} & \multicolumn{2}{|c|}{$95 \% \mathrm{Cl}$} \\
\hline & & & Lower & Upper & & & Lower & Upper \\
\hline \multicolumn{9}{|l|}{ Demographic factors } \\
\hline Gender & -0.40 & $0.67^{*}$ & 0.49 & 0.92 & -0.16 & 0.86 & 0.64 & 1.14 \\
\hline Age & -0.07 & 0.93 & 0.81 & 1.07 & 0.03 & 1.03 & 0.90 & 1.17 \\
\hline Health condition & -0.37 & $0.69^{*}$ & 0.51 & 0.95 & 0.10 & 1.11 & 0.83 & 1.48 \\
\hline \multicolumn{9}{|l|}{ Socioeconomic factors } \\
\hline Household income & -0.10 & $0.90^{*}$ & 0.82 & 0.99 & 0.04 & 1.04 & 0.95 & 1.13 \\
\hline Educational qualification & -0.08 & 0.93 & 0.54 & 1.60 & 0.17 & 1.19 & 0.74 & 1.91 \\
\hline Occupation & 0.00 & 1.00 & 0.95 & 1.06 & 0.07 & $1.07^{*}$ & 1.01 & 1.13 \\
\hline Type of real estate contract & -0.03 & 0.97 & 0.81 & 1.17 & 0.19 & $1.22^{*}$ & 1.01 & 1.46 \\
\hline \multicolumn{9}{|l|}{ Health behavior factors } \\
\hline History of smoking & -0.22 & 0.81 & 0.71 & 0.92 & -0.01 & $1.00 * * *$ & 0.88 & 1.13 \\
\hline Alcohol consumption & -0.04 & 0.96 & 0.85 & 1.09 & 0.06 & 1.06 & 0.93 & 1.21 \\
\hline Physical activity & -0.14 & 0.87 & 0.63 & 1.19 & 0.23 & 1.25 & 0.93 & 1.70 \\
\hline \multicolumn{9}{|l|}{ Psychosocial factors } \\
\hline Psychological distress & -0.50 & $0.61^{* * *}$ & 0.48 & 0.77 & 0.15 & 1.16 & 0.94 & 1.44 \\
\hline Depression & 0.99 & $2.68^{* *}$ & 1.37 & 5.24 & 0.74 & $2.10^{*}$ & 1.08 & 4.08 \\
\hline Social connectedness & -0.13 & 0.88 & 0.64 & 1.02 & 0.42 & $1.53^{* *}$ & 1.14 & 2.05 \\
\hline Self-rated health & -0.32 & $0.72^{* * *}$ & 0.60 & 0.87 & 0.54 & $1.69 * * *$ & 1.40 & 2.06 \\
\hline
\end{tabular}

$\operatorname{Exp} \beta$ refers to change in the odds ratio with a 1-unit change in the predictor.

SLE, subjective life expectancy; LE, life expectancy; $\mathrm{Cl}$, confidence interval.

${ }^{*} p<0.05,{ }^{* *} p<0.01,{ }^{* * *} p<0.001$.

masculine than women, such that the emphasis placed on the men role in this society may contribute to men's tendency to overestimate their LE. Socioeconomic factors influenced SLE.
Low household income, educational qualifications, occupation, and type of real estate contract were associated with pessimistic SLE estimates. People in low socioeconomic positions 
were a concern since they may underestimate their SLE. This underestimation could leave them vulnerable to underfunding their retirement [34], and therefore they might experience challenges during financial and career planning sessions [1].

All health behavior variables had an impact on an individual's estimation of their LE. Because individuals are aware that smoking, high alcohol intake, and low physical activity have a negative association with mortality through information disseminated in the public media, these factors caused individuals to view their LE more pessimistically [1]. It is interesting that participants who did not drink alcoholic beverages at all estimated their LE to be lower than people who consumed 1-4 drinks per month. Previous research has shown that the relationship between alcohol consumption and total mortality is U-shaped or J-shaped [35]. Several explanations have been proposed for this relationship. Persons who never drink alcohol might have given up drinking alcohol for health reasons, and the systematic underreporting of alcohol consumption may be possible. Misclassification must also be considered, as well as possible errors due to untruthful responses by respondents when asked about the frequency of drinking.

Psychosocial factors are internal representations of situations that are constructed based on unique life experience, perceptions, and understandings of the world [36]. Prior studies have proposed and tested a mental model for identifying the factors associated with SLE [37]. Distress, social connectedness, and self-rated health had a positive relation with SLE. Depression had a U-shaped relationship with the gap between SLE and actuarial LE. It may be the case that patients with depression have difficulty perceiving both their objective and subjective status clearly. Because the trade-off between realism and optimism explains these perceptions, they may exert many independent effects [38].

We established that people who expect to live longer than their actuarial LE tend to have a better education, to own their residence, to have less stress, to be more socially connected, and to evaluate their health more optimistically. This finding may encourage governmental policy initiatives on education, housing, and suicide that would be in line with expectations of increased longevity.

The results presented here should be interpreted with caution. First, the comparison with the 2015 Korean life tables was not precise, because compared with the population life tables, these data were drawn from a relatively small sample $(n=1000)$. Second, the method of administering the survey has several limitations. Online survey administration is limited in that not everyone has access to the Internet, and has been associated with a lower response rate than is found for paper surveys [39]. Moreover, the growth of Internet-based research has surpassed the development of ethical guidelines [40]. To moderate this problematic weakness of an online survey, we used a survey URL (opt-in survey), and all online panels were selected to be demographically balanced. Third, some limitations are present in the validation techniques, such as simulation and testing. However, the survey we describe included logic for verification techniques to be used in model checking, so we ensured that the quality of the survey method was satisfactory for verification and validation. A final potential problem is the restrictions on survey methodology that were present because we used cross-sectional data. To assess the impact of these factors, a time-trend study would be necessary in the future, involving a more in-depth investigation of these factors on a larger scale.

The strengths of this research include its theoretical basis and its examination of a comprehensive set of variables, extending prior research. Participants' SLE was found to be related to demographic, socioeconomic, health behavior, and psychosocial factors, and the presence of a gap between SLE and actuarial LE was associated with these four sets of variables. Public policies regarding the underestimation of SLE and its association with health risks need to be developed, and the issues raised by this study will be an important component of any such policy.

\section{ACKNOWLEDGEMENTS}

We thank Professor Young-Ho Khang for his guidance in writing this article. This study was supported by the Ministry of Health and Welfare (11-1352000-001549-01) and the Education and Research Encouragement Fund of Seoul National University Hospital.

\section{CONFLICT OF INTEREST}

The authors have no conflicts of interest associated with the material presented in this paper.

\section{ORCID}

Jaekyoung Bae http://orcid.org/0000-0002-7475-517X

Yeon-Yong Kim http://orcid.org/0000-0003-2179-8931

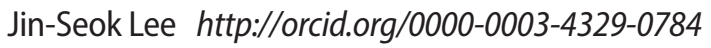




\section{REFERENCES}

1. Griffin B, Loh V, Hesketh B. A mental model of factors associated with subjective life expectancy. Soc Sci Med 2013;82:7986.

2. Lester D, Abdel-Khalek A. Some correlates of subjective life expectancy. Psychol Rep 2007;100(1):57-58.

3. Ross CE, Mirowsky J. Family relationships, social support and subjective life expectancy. J Health Soc Behav 2002;43(4):469489.

4. Tolor A, Murphy VM. Some psychological correlates of subjective life expectancy. J Clin Psychol 1967;23(1):21-24.

5. Hesketh B, Griffin B, Loh V. A future-oriented retirement transition adjustment framework. J Vocat Behav 2011;79(2):303314.

6. Michael D. Hurd MD, Smith JP, Zissimopoulos JM. The effects of subjective survival on retirement and social security claiming. J Appl Econ (Chichester Engl) 2004;19(6):761-775.

7. Bloom DE, Canning D, Moore M, Song Y. The effect of subjective survival probabilities on retirement and wealth in the United States. NBER Working Paper No. 12688; 2006 [cited 2017 Jul 10]. Available from: http://www.nber.org/papers/ w12688.

8. Khan MR, Rutledge MS, Wu AY. How do subjective longevity expectations influence retirement plans? [cited 2017 Jun 15]. Available from: http://crr.bc.edu/wp-content/uploads/2014/ 06/Panel-6_2-Khan-Rutledge-and-Wu.pdf.

9. van Solinge $H$, Henkens K. Living longer, working longer? The impact of subjective life expectancy on retirement intentions and behaviour. Eur J Public Health 2010;20(1):47-51.

10. Hamermesh DS, Hamermesh FW. Does perception of life expectancy reflect health knowledge? Am J Public Health 1983;73(8):911-914.

11. Mirowsky J, Ross CE. Socioeconomic status and subjective life expectancy. Soc Psychol Q 2000;63(2):133-151.

12. Siegel M, Bradley EH, Kasl SV. Self-rated life expectancy as a predictor of mortality: evidence from the HRS and AHEAD surveys. Gerontology 2003;49(4):265-271.

13. van Doorn C, KasI SV. Can parental longevity and self-rated life expectancy predict mortality among older persons? Results from an Australian cohort. J Gerontol B Psychol Sci Soc Sci 1998;53(1):S28-S34.

14. Pollock RL, Suyderhoud JP. An empirical window on rational expectations formation. Rev Econ Stat 1992;74(2):320-324.

15. Hamermesh DS. Expectations, life expectancy, and economic behavior. Q J Econ 1985;100(2):389-408.

16. Przeworski A. Public support for economic reforms in Poland. Comp Polit Stud 1996;29(5):520-543.

17. Mirowsky J. Subjective life expectancy in the US: correspondence to actuarial estimates by age, sex and race. Soc Sci Med 1999;49(7):967-979.

18. Nicholls N, Zimper A. Subjective life expectancy. In: Whitbourne SK, editor. The encyclopedia of adulthood and aging. Malden: Wiley Blackwell; 2016, p. 1-9.

19. Park EG. Socio-economic factors affecting subjective expectations of longevity: analysis of KrelS 2005 [dissertation]. Seoul: Seoul National University; 2008 (Korean).

20. Rappange DR, van Exel J, Brouwer WB. A short note on measuring subjective life expectancy: survival probabilities versus point estimates. Eur J Health Econ 2017;18(1):7-12.

21. Rappange $D$, van Exel J, Brouwer W. Measuring subjective life expectancy: survival probabilities versus point estimates. In: Rappange $\mathrm{D}$, editor. Future health: a policy and an individual perspective. Rotterdam: Erasmus University Rotterdam; 2016, 153-165.

22. Korea Centers for Diseases Control and Prevention. Community Health Survey 2016 [cited 2017 May 8]. Available from: https://chs.cdc.go.kr/chs/index.do (Korean).

23. Morrill R, Cromartie J, Hart G. Metropolitan, urban, and rural commuting areas: toward a better depiction of the United States settlement system. Urban Geogr 1999;20(8):727-748.

24. Shin IS. Parents' perception comparison based on their social economic status on the operations of Seoul autonomous schools. J Soc Sci 2012;27(2):133-151 (Korean).

25. Kim KH. The impact of family background on educational continuation across school transitions. Korean J Sociol 2004; 38(5):109-142 (Korean).

26. Bickel WK, Odum AL, Madden GJ. Impulsivity and cigarette smoking: delay discounting in current, never, and ex-smokers. Psychopharmacology (Berl) 1999;146(4):447-454.

27. Korea Centers for Disease Control and Prevention. $2010 \mathrm{Na}-$ tional Health Interview Survey (NHIS) public use data release; 2011 [cited 2017 Mar 31]. Available from: http://kosis.kr/statisticsList/statisticsList_01List.jsp?vwcd=MT_ZTITLE\&parent Id =A\#SubCon (Korean).

28. Manson JE, Nathan DM, Krolewski AS, Stampfer MJ, Willett WC, Hennekens $\mathrm{CH}$. A prospective study of exercise and incidence of diabetes among US male physicians. JAMA 1992;268 (1):63-67.

29. Mihalopoulos C, Chen G, lezzi A, Khan MA, Richardson J. As- 
sessing outcomes for cost-utility analysis in depression: comparison of five multi-attribute utility instruments with two depression-specific outcome measures. Br J Psychiatry 2014; 205(5):390-397.

30. Kaplan GA, Camacho T. Perceived health and mortality: a nine-year follow-up of the human population laboratory cohort. Am J Epidemiol 1983;117(3):292-304.

31. Idler EL, Benyamini Y. Self-rated health and mortality: a review of twenty-seven community studies. J Health Soc Behav 1997; 38(1):21-37.

32. Wolinsky FD, Miller TR, Malmstrom TK, Miller JP, Schootman M, Andresen EM, et al. Self-rated health: changes, trajectories, and their antecedents among African Americans. J Aging Health 2008;20(2):143-158.

33. Korean Statistical Information Service. Life table 2015 [cited 2017 Jan 17]. Available from: http://kosis.kr/statisticsList/ statisticsList_01List.jsp?vwcd=MT_ZTITLE\&parentld = A\#Sub Cont (Korean).

34. Barr N, Diamond P. The economics of pensions. Oxf Rev Econ Policy 2006;22(1):15-39.
35. Berger K, Ajani UA, Kase CS, Gaziano JM, Buring JE, Glynn RJ, et al. Light-to-moderate alcohol consumption and the risk of stroke among U.S. male physicians. N Engl J Med 1999;341 (21):1557-1564.

36. Langan-Fox J, Anglim J, Wilson JR. Mental models, team mental models, and performance: process, development, and future directions. Hum Factors Ergon Manuf 2004;14(4):331352.

37. Australian Institute of Health and Welfare. Australia's health 2012 [cited 2017 Jun 30]. Available from: http://www.aihw. gov.au/publication-detail/?id=10737422172.

38. Mirowsky J, Ross CE. Control or defense? depression and the sense of control over good and bad outcomes. J Health Soc Behav 1990;31(1):71-86.

39. Handwerk PG, Carson C, Blackwell KM. On-line vs. paper-andpencil surveying of students: a case study. AIR 2000 annual forum paper; 2000 [cited 2017 Jun 30]. Available from: https: //eric.ed.gov/?id=ED446512.

40. Eysenbach G, Wyatt J. Using the Internet for surveys and health research. J Med Internet Res 2002;4(2):E13. 